\title{
Vamos de mãos dadas: Drummond leitor de Camões em A Paixão Medida
}

\author{
Daniel Soares Duarte ${ }^{1}$
}

\begin{abstract}
RESUMO: Neste artigo, apresento uma interpretação de alguns poemas do livro A paixão medida, de Carlos Drummond de Andrade, tendo em vista seu intertexto com a poesia de Luiz Vaz de Camões. Tratam-se de oito poemas dispostos no livro do poeta brasileiro que podem ser lidos como suporte fundamental à investigação de Drummond acerca da literatura como presença de vida após a morte: evocando Camões em forma, tom e em tópicos, explicitando a recepção do poeta lusitano na extensão dos versos, Drummond trabalha para viver além da vida, tema presente na totalidade do livro citado bem como nos temas dos poemas aqui elencados. Tal estratégia reflete parâmetros da estética da recepção conforme organizados por Hans Robert Jauss e Wolfgang Iser.
\end{abstract}

PALAVRAS-CHAVE: Luiz Vaz de Camões; Carlos Drummond de Andrade; Estética da recepção; Poesia em língua portuguesa; História da literatura.

\section{Let's go together hand in hand: Drummond Camões' reader in A Paixão Medida}

\begin{abstract}
In this paper, I present an interpretation of some poems from the book A paixão medida by Carlos Drummond de Andrade, while considering them as intertexts with the poetry of the great poet Luiz Vaz de Camões. A total of eight poems present in Drummond's book can be read as a core support to the Brazilian poet's investigation about how, in literature, one can survive after death: by evoking Camões in poematic form, tone and subjects, and by explicitly the reception of the Portuguese poet in verse extension, Drummond works to live beyond life itself; this theme is present fully in the whole book, as well as in the themes of the poems I analyze here. This strategy reflects parameters of Reception Theory as they were presented by Hans Robert Jauss and Wolfgang Iser.
\end{abstract}

KEYWORDS: Luiz Vaz de Camões; Carlos Drummond de Andrade; Reception theory; Portuguese language poetry; Literary history.

Neste trabalho, meu intuito é investigar a relação entre a poesia camoniana e a drummondiana através da abordagem de Carlos Drummond de Andrade como leitor de Camões no livro A paixão medida (ANDRADE, 2002). Viso considerar a historicidade dessa poética; não uma historicidade de fora para dentro, isto é, aquela conferida pela crítica e pela história tradicional da literatura; mas uma historicidade de dentro para fora, retirando da própria obra de Drummond os caracteres que lhe conferem história e historicidade. Viso também compreender a evocação a Camões ao longo do livro em forma, conteúdo e assunto, o que será verificado na análise dos poemas pertinentes. Para tanto, utilizo-me do arcabouço da estética da recepção, que considera a literatura através de parâmetros outros que não os da história tradicional da literatura, partindo primordialmente de uma análise da recepção dos textos

\footnotetext{
${ }^{1}$ Professor do Bacharelado em Tradução Inglês-Português da Universidade Federal de Pelotas.
} 
poéticos, sem privilegiar posições sociológicas, em que seria tão comum o texto enfocado tornar-se pretexto para o estudo de tópicos outros que não a literatura.

Lanço mão do texto inaugural da estética da recepção, onde Hans Robert Jauss expõe suas teses (JAUSS, 1994), desenvolvidas posteriormente. Utilizo-me ainda do texto de Regina Zilbermann, Estética da recep̧̧ão e história da literatura, que abarca os textos e estudos importantes de Jauss (ZILBERMANN, 1989), e do artigo “A interação do texto com o leitor”, de Wolfgang Iser, que trata dos vazios do texto e da relação entre eles e o sentido (in LIMA, 1979, p. 88132). Para adentrarmos os caminhos da recepção de Drummond, abordarei os textos de $A$ paixão medida que podem ter, já à primeira vista, alguma relação mais direta com a poesia de Camões, analisando-os para buscar sua historicidade via recepção.

Para acessarmos uma leitura possível no corpus escolhido, é necessária a análise do material poético em seus vários aspectos, formais e de conteúdo. Começo pela escolha dos textos apropriados dentro do corpus escolhido.

A paixão medida é obra já madura de Drummond. Lançado em 1980, após a trilogia da poesia autobiográfica de Boitempo, o livro incorpora poemas ontológicos, poemas metalinguísticos, também poemas historiográficos mais que autobiográficos. O eu-lírico Drummond volta de sua investigação do passado biografado, postando-se novamente frente à vida. Ainda em sua postura de gauche, o eu-lírico encara o mundo presente pela indagação e experienciação fenomenológica e ontológica. Pari passu, o teor camoniano é sentido em vários textos. Dos trinta e quatro poemas do livro, oito remetem à poesia camoniana, seja em forma, como nos sonetos mais ou menos camonianos (talvez "Confronto" seja o mais camoniano de todos), a ele remetendo na forma de utilizar-se da língua, seja em ter Camões como tema poético: os dois últimos poemas do livro, "História, coração, linguagem" e "O poeta", são desbragadas homenagens a Camões. Tendo em vista que na obra poética drummoniana não existem acidentes ou espaços para arbitrariedades, esses dois últimos poemas não se encontram ao fim do livro por acaso, e o número de textos referentes a Camões é relativamente pequeno apenas na aparência. Minha tese é a de que o desejo de durar faz remeter a Camões, e esse desejo é tanto 1) matéria de labor e mentação poética quanto 2) possibilidade de duração, de perpetuar-se. Ambos os momentos só podem se dar plenamente no momento da recepção dos textos. Vamos a ela. Os textos escolhidos são "Os cantores inúteis”, “Ante um nu de Bianco”, “O nome”, "Confronto”, “Água-desfecho”, “A palavra”, "História, coração, linguagem” e "O poeta".

"Os cantores inúteis" (ANDRADE, 2002, p. 29) é, formalmente, um soneto em decassílabos heróicos e brancos. O léxico possui, em destaque, um reiterado número de 
adjetivos, alguns em uso bastante incomum (pássaro flautista, canção absoluta, instrumentos não-terrestres, etc.). O estrato fônico não possui fonema reiterativo forte, mas é por outro lado variado, rico em consoantes e em vogais abertas. A sintaxe mostra alguns encadeamentos, como em "Um pássaro flautista no quintal / caçoa de meu verso modernista." (v. 1 e 2), e "Os amantes que passam, distraídos / e surdos a tais cantos discordantes" (v. 11 e 12). Ocorre também o hipérbato em "vence o mítico amor nossa vaidade" (v. 10). O eu-lírico discorre inicialmente sobre a mofa que um pássaro faz de seu verso. No verso cinco, diz que a canção absoluta não se escreve. Nem pássaro nem poeta alcançam a canção imorredoura, mas apenas o amor, que torna surdos os amantes que passam, distraídos. Para eles, governados pela melodia interna, tudo mais são ruídos. Temos aqui um exemplo do que Friedrich chamou de idealidade vazia: tentar alcançar diretamente os planos metafísicos via língua é inviável pela própria natureza da língua (ver FRIEDRICH, 1978, p. 48; também INGARDEN, 1973, p. 269 e ss.). Os cantos do poeta e do pássaro transformam-se em ruídos devido ser impossível à materialidade de ambos corresponder aos estados transcendentes aos do mundo dos fenômenos (no texto, a transcendência está metaforizada pela expressão "melodia interna”).

Esse soneto, que pouco aparenta de camoniano e se constrói como um soneto modernista e moderno, é passo inicial que irá se aprofundar ao longo do livro e dos outros poemas. O imediatamente próximo, “Ante um nu de Bianco" (ANDRADE, 2002, p. 31), adentra em apuros formais, perfazendo um soneto clássico, de claro sabor camoniano. Enquanto o soneto anterior possuía encadeamento e hipérbato, este possui todos os elementos roubados a Camões.

\footnotetext{
Quanto mais vejo o corpo, mais o sinto existente em si mesmo, proprietário de um segredo, um sentido - labirinto particular, alheio ao ser precário.
}

As rimas, a sintaxe quebrada, que encadeia os versos e os complexifica; o teor filosófico das considerações; a riqueza linguística, fonética; os decassílabos heróicos: por esses caracteres não se pode dizer, ainda, que é Camões o autor lido. Isto se faz pouco a pouco, e o próximo passo significativo nesse sentido é justamente o próximo soneto, "O nome".

Encapelou-se o mar, um nome ouvindo.

Feras emudeceram. Da montanha um rumor rubro e pânico, infletindo sobre a cidade, entontecida aranha, 
trouxe consigo o pó do tempo findo

e das coisas morrentes, em tamanha

desolação que, tudo consumindo,

desse nome crescia a força estranha. (p. 53)

Camonianamente construído, o poema inicia falando do mar, que se enfurece ouvindo um nome. Ao mesmo tempo, da montanha desce um rumor que a tudo consome. O eu-lírico pergunta que poder há nesse nome, nas sílabas cruéis e musicais (v. 10), "que ficam revoando e reboando entre espirais / convulsas de um amor não mais amando?’. O poema termina com uma indagação, propiciando a continuação do texto na mente do leitor devido à questão não respondida, bem como a sequência em direção a outro texto: que nome será esse? É novamente a metalinguística como salvação da poesia frente à falácia do mundo real em literatura? Se o é, não é apenas isto. Há um nome que enfurece o mar, que faz as montanhas tremerem, um nome a que somos levados. O texto de Iser, supracitado, estuda a relação entre o não dito, os chamados vazios do texto, e o papel do leitor como estruturador do texto em seu sentido (é sempre preciso lembrar do processo comunicacional, portanto dialético, envolvido na leitura; assim, o texto torna-se também estruturador do leitor e seu determinante ao longo desta). Em um texto onde as perguntas (também implícitas, mas no caso explícitas) não se respondem na sequência da leitura, cabe ao leitor estabelecer conexões mínimas para propiciar respostas ao texto (e mesmo as respondidas geram necessidade de combinação para que se gere o sentido, em maior ou menor grau). Nas palavras do próprio Iser, os vazios possibilitam as relações entre as perspectivas de representação do texto e incitam o leitor a coordenar estas perspectivas (ISER, 1979, p. 91). Os dois tercetos do poema "O nome" são formados por perguntas acerca das sílabas do nome evocado no título. São perguntas não respondidas acerca da natureza desse nome. Mas esses vazios se ampliam devido à indeterminação relativa ao próprio nome, não explicitado pelo texto. Para suprir ou preencher esse vazio específico, ao mesmo tempo mantendo-me dentro do corpus, busquei esquematizar o que o texto determina, preenchendo os vazios com determinações presentes em outros textos do mesmo corpus, assim seguindo as ideias de Iser, para quem “à medida que os vazios indicam uma relação potencial, liberam o espaço das posições denotadas pelo texto para os atos de projeção do leitor. Assim, quando tal relação se realiza, os vazios 'desaparecem”' (ISER, 1979, p. 106). O nome vai-se determinando aos poucos. O eu-lírico dirá, em “A palavra” (ANDRADE, 2002, p. 79): "Quero só a palavra / que nunca estará neles [os dicionários] / nem se poderá inventar. // Que resumiria o mundo / e o substituiria". Um nome que enfurece o mar, uma palavra que a tudo resumiria. Onde encontrar preenchimento para tal vazio?

O penúltimo poema do livro, "História, coração, linguagem” (p. 115), em seus últimos 


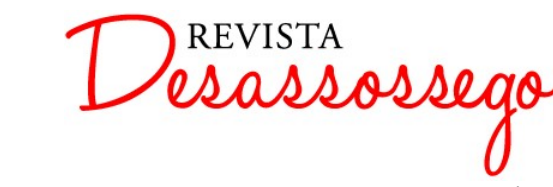

versos, aponta qual é o nome/palavra.

Já tenho uma palavra pré-escrita
que tudo exprime quanto em mim se turva.
Pelos antigos e pelos vindouros
foste discurso de geral amor.
Camões - oh som de vida ressoando
em cada tua sílaba fremente
de amor e guerra e sonho entrelaçados...

O nome, em língua portuguesa, sinônimo de soneto, de poesia, de Amor, acaba por fim determinando-se. Aparece aqui na relação entre a palavra material, som e forma, e o seu sentido, que não está na palavra material. Essa palavra é o nome Camões, vista aqui como "som" de vida ressoando, não como material escrito, portanto nunca estará nos dicionários (ou não apenas neles), mas antes na língua falada e no pensamento, na vida. A homenagem explícita a Camões encontra-se ao fim do livro, e é necessário então retornar e reler, para verificar se a explicitação do nome pode determinar certos vazios. Torna-se assim possível relacionar o nome evocado como sendo o de Luís Vaz de Camões no camoniano soneto "O nome", bem como tornar também homenagem a apresentação de vários sonetos presentes na obra, camonianos em forma, em conteúdo ou ambos, tais como "Confronto", “Água-desfecho”, "Ante um nu de Bianco".

Dos textos ainda não mencionados, talvez "Confronto" (p. 55) e “Água-desfecho" (p. 71) sejam os mais formalmente camonianos. O primeiro é uma fábula em que Amor e Loucura se personalizam e dialogam. Amor, o tema camoniano por excelência, deseja pouso na casa da Loucura, devido aos desvarios a que sua paixão o conduziu. A Loucura reluta, mas aceita ao vê-lo, de humano que era, assim tão inumano. E sai, dizendo não conhecer mais triste desatino “que este mal sem perdão, o mal de amar". O Amor cansado busca na Loucura o seu repouso, mas nem a Loucura fica como sua companheira. É seu destino amar só. Os decassílabos, em sua maioria heróicos, possuem um tratamento estilístico clássico, tendo em Camões seu primeiro e maior representante em língua portuguesa. Esse amor abrigado na casa da loucura remete também ao soneto "O nome", onde as sílabas desse nome revoam entre as espirais de “um amor não mais amando". Próximo ao nome, que é a palavra Camões, o Amor. Novamente, o Amor como mal, o mal de amar, o amor não mais amando. Visão negativa do amor? Não. Apenas uma das faces. Amor com viés negativo pode aqui significar uma etapa em seu fim, um bem do qual se deve desapegar para se seguir adiante. Essa questão leva ao próximo soneto, “Água-desfecho”, e leva também, dentro desse soneto, à relação de duração, de escape da morte em direção a uma vida, se não eterna, mais duradoura. 
“Água-desfecho” é também um soneto clássico, embora apresente marcas não apenas camonianas, mas também do simbolismo, um pouco longe do tom grandiloquente dos demais sonetos do livro, maneiristas e barrocos (à exceção, já vista, de "Os cantores inúteis", mais modernista em suas imagens). Estudá-lo significa adentrar outras facetas presentes e possíveis, nas quais uso outras abordagens que não apenas a estética da recepção. Entretanto, dada a importância desse soneto para a obra como um todo e para o estudo da recepção de Camões por Drummond, é parada necessária e válida. Transcrevo-o aqui para análise.

\author{
Un peu profond ruisseau calomnié \\ desce em meu rumo, vem-se aproximando. \\ Sem o ouvido sutil de Mallarmé, \\ ouço-lhe embora o ruído grave e brando. \\ Bóiam fanadas coisas na corrente: \\ uma quermesse, vozes, o violino, \\ em febre ouvido, a cor de uma serpente \\ enovelada sobre o meu destino. \\ Já provo o antessabor da linfa amara \\ a penetrar-me a língua e a percorrer \\ o mais furtivo poro de consciência. \\ Pois submergindo estou, a vida é clara, \\ e não mais necessita de clemência \\ o epilogado, esvaecido ser.
}

Um dos textos-chave de A paixão medida, em “Água-desfecho” o pressentimento sobre a morte se faz presente. É sintomático que tal poema se apresente no livro de Drummond posteriormente ao bem conhecido estudo de Affonso Romano de Sant'Anna, Drummond, o gauche no tempo. Tratando desse ser gauche no transcurso temporal, Sant'Anna chegará ao estudo da consciência da morte, da destruição na poesia drummondiana.

É significativo que a consciência da destruição se torne mais aguda ao constatar o poeta a ação demolidora do tempo sobre seu próprio corpo. Estabelece-se uma interrelação (sic) entre o seu físico e os outros elementos ao redor. (...) Tendo absorvido a história e transitado prenhe de temporalidade, o preço que paga por se incorporar ao fluxo vital é o de sua própria destruição. (SANT’ANNA, 1972, p. 150)

Essa consciência da destruição é também, ainda segundo Sant'Anna, muitas vezes explicitada através de uma relação com o elemento água, dada a simbologia que esta carrega como portadora da vida e da morte. 
Num poeta onde a preocupação temporal é latente em todo o transcurso de sua obra, e onde a maioria das metáforas então (sic) prenhes de temporalidade, os referentes aquáticos, mesmo quando não relacionados abertamente com a idéia de tempo, tendem a se inscrever no mesmo tópico. (SANT'ANNA, 1972, p. 159)

Assim, água e fim, desfecho, encontram-se explícitos e presentes no soneto. As estrofes, embora não aparentem, narram o fluxo de vida/morte em seu trajeto, de sua aproximação: a referência explícita a Mallarmé cria ligações acerca do teor metafísico expresso no soneto. A intertextualidade, na citação quase completa do verso referido, mostra como o engenho do poeta soube indicar diretamente, ainda que sem palavras, a morte. O primeiro verso do soneto drummondiano retira quase todo o último verso do soneto "Tombeau de Paul Verlaine", de Mallarmé. Comparando, temos um soneto alexandrino no poeta francês e um decassílabo em Drummond, que cortou as duas últimas sílabas do verso mallarmaico: "la mort", no original ${ }^{2}$. A morte desce em direção ao eu-lírico, na primeira estrofe. Na segunda, a memória traz pedaços de vivências e entre elas a cor de uma serpente / enovelada sobre meu destino, essa serpente como símbolo da perecibilidade (visto ser a serpente o elemento corruptor no mito da criação; convencendo Eva a comer o fruto e dá-lo a Adão, acaba por trazer a morte ao gênero humano); chegando à terceira estrofe, onde a linfa amara, o líquido de gosto quiçá desgostoso do fim da encarnação, pelo apego à vida, até chegar à completa submersão na última estrofe, onde o “epilogado, esvaecido ser”, agora escoando na corrente e já deixando de ser, sabe ser a vida clara; daí a clemência desnecessária, pois a pedem aqueles que não entendem a corrente aquosa e fluida, ou que a não acompanham.

O soneto estudado é elemento constitutivo de um livro em que o existir em face da morte é tema global. A intensa pessoalidade da poesia drummondiana possibilita comparar sua obra e sua biografia. À época do lançamento de A paixão medida, Drummond adentrava seus setenta e oito anos. Sentindo e presenciando o passar do tempo em si, aproximando-se de seu fim neste plano, ou, mesmo que nada sentisse, sendo um homem sensibilíssimo e sabendo que seu tempo aqui não seria tão longo, o eu-lírico expressa a vivência da consciência humana, pesando sua vida ao aproximar-se do fim, o mundo à sua frente, pensando na metafísica possível no post mortem, contando suas histórias restantes, lembrando dos que o precederam, e também tentando durar. Esse desejo, de permanecer, de existir além de si mesmo sem no entanto abandonar a si, leva o eu lírico de volta à linguagem. Miguel Sanchez Neto dirá, na introdução do mesmo livro: "Diante das falácias que são o ser e o mundo, o poeta volta-se para

\footnotetext{
${ }^{2}$ Disponível em http://poetry.poetryx.com/poems/8776. Acesso em 10/08/2018.
} 
outro possível existencial. O possível da linguagem.” (em ANDRADE, 2002, p. 10). Também a linguagem tem um nome que a define. Em "História, coração, linguagem", falando a Camões, Drummond dirá: "És a linguagem” (p. 116).

Mas qual o motivo da conexão explícita com Camões para fazer ressaltar a linguagem como realidade duradoura? Jauss, ao apresentar suas teses acerca da estética da recepção, diz, na segunda tese, que

\begin{abstract}
a obra que surge não se apresenta como novidade absoluta num espaço vazio, mas, por intermédio de avisos, sinais visíveis e invisíveis, traços familiares ou indicações implícitas, predispõe seu público para recebê-la de uma maneira bastante definida. Ela desperta a lembrança do já lido, enseja logo de início expectativas quanto a "meio e fim", conduz o leitor a determinada postura emocional e, com tudo isso, antecipa um horizonte geral da compreensão vinculado, ao qual se pode, então - e não antes disso - colocar a questão acerca da subjetividade da interpretação e do gosto dos diversos leitores ou camadas de leitores. (JAUSS, 1994, p. 28)
\end{abstract}

Temos, indiretamente colocada, a resposta à pergunta acima. Outros poetas são indicados no texto, mas apenas Camões é "homenageado" na medida poética justa: com poesia, despertando de modo explícito a lembrança do já lido. Fazendo isso, a obra vincula-se ao nome e à importância do poeta maior da língua portuguesa, na tentativa de durar além da existência objetiva do homem Drummond. Entre os fatores apontados por Jauss para predispor o público em relação a determinada obra, está a relação implícita com obras conhecidas do contexto histórico-literário (JAUSS, 1994, p. 29). Drummond sabe que a poesia camoniana durou por séculos devido não apenas a méritos extraliterários, mas, ao contrário, devido à sua plena realização como linguagem, como canto. Os dois primeiros versos de "História, coração, linguagem" são, justamente, "Dos heróis que cantaste, que restou / senão a melodia do teu canto?”. Vincular-se com êxito ao mestre da língua, através da evocação em forma (nos sonetos, nos versos decassílabos, na grandiloquência lexical, no arranjo sintático), em conteúdo (tematizando, nos sonetos, o amor, a transcendência, a língua como realidade durável), e em dois poemas específicos, os últimos do livro, em homenagem explícita ao poeta, é querer vincular-se ao sistema da literatura de língua portuguesa diretamente em uma de suas raízes, na qual grandes nomes produziram obras de alta qualidade.

Os decassílabos de "História, coração, linguagem" estão cheios de itens lexicais que, somados, apontam Camões desde o início. "As armas em ferrugem se desfazem, / os barões nos jazigos dizem nada": dois versos que apontam para a estrofe inicial de Os Lusíadas. Assim, os itens oceano, deuses, ninfas, somam-se ao longo dos versos lidos, projetando um campo e criando um horizonte de leitura, a partir do qual os vazios vão induzindo o leitor para que este 
faça agir as posições manifestadas (ISER, 1979, 131). Antes de virarmos a página, desde que haja certa instrumentalização por parte do leitor, sabemos ser Camões a figura a quem o louvor é dirigido. Mesmo após o vocativo ser explicitado (verso 28), seguem-se referências à obra camoniana, por exemplo, no verso “és, mais que amador, o próprio amor”, referência imediata ao soneto "Transforma-se o amador na coisa amada...". Também certos itens e estratégias de sintaxe realizam-se camonianamente. Os itens utilizados antiteticamente nos versos "e nisto se resume a irresumível / humana condição no eterno jogo / sem sentido maior que o de jogar" são partes de estratégias copiadas a Camões, por exemplo nos versos “Ah! minha Dinamene! Assi deixaste / quem não deixara nunca de querer-te?", ou em "É um contentamento descontente" e "É um não querer mais que bem querer", onde a negação tanto se estabelece nos elementos entre sintagmas como pertencentes ao mesmo sintagma.

Tal estratégia gera um horizonte de expectativa para a leitura dos versos de Drummond, conectando-os aos versos e à obra de Camões. Jauss, ao discorrer acerca da distância estética, o faz como a mediação "do horizonte de expectativa preexistente e a aparição de uma obra nova - cuja acolhida [por público e crítica] (...) pode ter por consequência uma 'mudança de horizonte" (JAUSS, 1994, p. 31). A homenagem/referência a Camões não aparece aqui, entretanto, em termos de mudança de horizonte. Não há refutação; ao invés, há a exaltação. Por este motivo, é possível dizer que a conexão ao mundo camoniano é feita no intuito/desejo de duração além do tempo da vida do poeta. Os três versos, já acima citados, "Já tenho uma palavra pré-escrita, que tudo exprime quanto em mim se turva. / Pelos antigos e pelos vindouros", delineiam vazios a serem preenchidos. O que se turva no eu-lírico é a vida que se escoa, a própria existência. A leitura de outros textos de $A$ paixão medida, como "A morte a cavalo”, se perfaz em horizonte para o preenchimento deste vazio. O eu-lírico sabe que Camões irá durar, pois que foi discurso "de geral amor, pelos antigos e pelos vindouros". Isto é, além da vida presente, no tempo sem fim. Louvar Camões é, entre outras possibilidades, fazer durar a si em linguagem na posteridade. Não há casualidade na lírica drummondiana, repito. Do mesmo modo, não há determinismo.

Por que quereria Drummond buscar Camões como sustentáculo para sua poesia? Ele, que se considerava poeta menor (ver, por exemplo, o "Canto ao homem do povo Charlie Chaplin”. ANDRADE, 2002b.), excêntrico no sentido literal, aquele que está fora do centro, gauche por chamamento, também deseja durar. Viver assim tão próximo da morte, sentindo-a a cada pensamento, emoção ou percepção, é instância que dá urgência de perpetuar-se. Os que amam a vida querem vivê-la, e esse som de vida ressoando nas sílabas de Camões (expressão dúbia, por fazer referência tanto às sílabas do nome Camões quanto às sílabas das palavras 
escritas por Camões) é lastro que reacende a chama de quem as lê e as canta.

\section{Referências:}

ANDRADE, Carlos Drummond de. A paixão medida. Rio de Janeiro: Record, 2002.

ANDRADE, Carlos Drummond de. Poesia completa. Rio de janeiro: Nova Aguilar, 2002.

FRIEDRICH, Hugo. Estrutura da lírica moderna. São Paulo: Livraria Duas Cidades, 1978.

INGARDEN, Roman. A obra de arte literária. Lisboa: Fundação Calouste Gulbekian, 1973.

ISER, Wolfgang. A interação do texto com o leitor. In: LIMA, Luiz Costa (org.). A literatura e o leitor. Textos de estética da recepção. Rio de Janeiro: Paz e Terra, 1979. Tradução de Luis Costa Lima, p. 83-132.

JAUSS, Hans Robert. A bistória da literatura como provocação à teoria literária. São Paulo: Ática, 1994. Tradução de Sérgio Tellaroli.

MALLARMÉ, Stéphane. Tombeau De Paul Verlaine. Disponível em http://poetryx.com/poetry/poems/8776. Acesso em 10/08/2018.

SANCHEZ NETO, Miguel. A riqueza do vocábulo. In: ANDRADE, Carlos Drummond de. A paixão medida. Rio de Janeiro: Record, 2002, p. 7-15.

SANT'ANNA, Affonso Romano de. Drummond, o gauche no tempo. Rio de Janeiro: Lia; Instituto Nacional do Livro, 1972.

ZILBERMANN, Regina. Estética da recepção e história da literatura. São Paulo: Ática, 1989. 